\title{
Analysis of a functional serotonin transporter promoter polymorphism in psoriasis vulgaris
}

\author{
Rotraut Mössner • Gerthild Stiens • Inke R. König • \\ Diane Schmidt • Anja Platzer · Ullrich Krüger • \\ Kristian Reich
}

Received: 21 July 2008 / Revised: 22 September 2008 / Accepted: 30 September 2008 / Published online: 1 November 2008

(C) The Author(s) 2008. This article is published with open access at Springerlink.com

\begin{abstract}
Serotonin is a monoamine acting as a neuromediator in the central and peripheral nervous system. Recently, serotonin has also been shown to influence T- and B-cell function. The serotonin transporter is central in the regulation of the serotonergic system and widely expressed on cells of the immune system. A functional length polymorphism in the promoter of the serotonin transporter gene (5-HTTLPR) has been implicated in the genetic background of depression. Psoriasis is a complex disease with a polygenetic inheritance. In light of the role of T-cell mediated inflammation in psoriasis and the increased prevalence of depression in psoriatic patients, we analyzed the 5HTTLPR polymorphism in 309 patients with psoriasis vulgaris and 315 healthy control individuals. No significant differences in genotype distribution and allele frequencies were found. There was also no difference in the score of the Hamilton Rating Scale for Depression in patients with psoriasis $(n=137)$ characterized by carriage of different 5HTTLPR genotypes. These findings argue against a major contribution of the 5-HTTLPR polymorphism to psoriasis
\end{abstract}

R. Mössner $(\bowtie) \cdot$ D. Schmidt · A. Platzer · U. Krüger

Department of Dermatology, Georg-August-University,

Von-Siebold-Strasse 3, 37075 Göttingen, Germany

e-mail: rmoessn@gwdg.de

\section{G. Stiens}

Gerontopsychiatrisches Zentrum, Rheinische Kliniken Bonn,

Kaiser-Karl-Ring 20, 53111 Bonn, Germany

\section{R. König}

Institute of Medical Biometry and Statistics,

University of Lübeck, Ratzeburger Allee 160,

23538 Lübeck, Germany

K. Reich

Dermatologikum, Hamburg, Stephansplatz 5,

20354 Hamburg, Germany susceptibility and the occurrence of depressive symptoms among psoriatic patients.

Keywords Psoriasis · Genetics · Depression .

Serotonin $\cdot 5$-HTTLPR

\section{Introduction}

Psoriasis vulgaris is a complex disease with multifactorial inheritance affecting approximately $2-3 \%$ of the population. It is believed that cells of the innate and acquired immune system, among them dendritic cells and T-cells, collaborate to produce a pattern of cutaneous angiogenesis, inflammation and epidermal changes that underlie the formation of sharply demarcated erythematosquamous plaques, the typical clinical presentation of psoriasis [3]. Because psoriasis is a chronic, often widespread and stigmatizing condition that may extensively reduce the quality of life of affected patients, the observed increased prevalence of depressive symptoms among patients compared with healthy individuals [1] can possibly be regarded as secondary to the manifestation of a significant medical condition. It is also not excluded that the psoriatic inflammatory process plays a direct role via the constantly increased production of mediators that may also influence mental functions or that psoriasis and depression share common risk factors at the genetic level. On the other hand, it has been suggested that stress can aggravate skin inflammation in patients with psoriasis, indicating another level of possible interactions between psychological symptoms and skin inflammation.

The serotonergic system is a promising candidate for establishing a neuroimmunological link between psoriatic skin disease and psychological symptoms. In the central 
nervous system, serotonergic neurons project to almost all regions of the brain and influence many physiological functions such as pain, sleep, motor functions, neuroendocrine circuits and the mood. The main producers of 5-HT are enterochromaffin cells of the gut and the serotonergic neurons of the brain, but 5-HT is stored in many cell types outside the central nervous system including platelets, lymphocytes, monocytes/macrophages and dendritic cells [6]. Recently, it has been shown that lymphocytes also synthesize and excrete 5-HT [17]. The production of 5-HT is increased at sites of inflammation and several functional activities of 5-HT have been revealed that play an important role in chronic inflammatory diseases such as psoriasis including the activation of mast cell migration and adhesion [9], the stimulation of cytokine release from dendritic cells [8] and the mediation of dendritic cell-T-cell interactions [17].

The expression and function of the serotonin transporter (5-HTT), which is responsible for the uptake of 5-HT into cells thereby removing 5-HT from the extracellular space, is a key parameter in the regulation of 5-HT-mediated effects in the central nervous system and the immune system [15]. The expression of 5-HTT is controlled by a repeat length polymorphism in the 5-HTT linked polymorphic region (5-HTTLPR). The long (high activity) allele of this polymorphism is associated with a higher number of 5HTT molecules on lymphocytes [10]. The biological relevance of the 5-HTTLPR polymorphism is underscored by the recent finding of an association with primary pulmonary hypertension [5], and the observed influence on the development of depressive symptoms in individuals afflicted by a negative life event as well as on suicidal behavior [11].

In this study, we used a case-control design to obtain first evidence whether the 5-HTTLPR polymorphism is associated with psoriasis. We also compared depressive symptoms in psoriatic patients characterized by carriage of different 5-HTTLPR genotypes.

\section{Subjects and methods}

Study participants

Unrelated German Caucasian patients with an established diagnosis of chronic plaque-type psoriasis were enrolled from the Department of Dermatology, University Hospital Göttingen (309 individuals, 127 female, 182 male, age $46.0 \pm 14.3$ years (mean $\pm \mathrm{SD}$ ), positive family history in 140 cases). The control group consisted of healthy unrelated German Caucasians without a personal or family history of psoriasis (315 individuals, 146 female, 169 male, age $35.6 \pm 12.1$ years (mean $\pm \mathrm{SD}$ )) recruited from the blood donor registry of the Department of Transfusion
Medicine, University Hospital Göttingen and from local health-care personnel as described previously [20].

To assess the presence of depressive symptoms, the Hamilton Rating Scale for Depression (HAM-D) was performed in the subgroup of 137 patients of patients aged between 18 and 60 years who were recruited between May 2004 and November 2005. The HAM-D is a validated scale that is routinely used for the assessment of depression and rates the severity of 21 symptoms typical of depression, from which a sum score is calculated. The HAM-D can take on values between 0 and 67 , and the score of $>8,>14$ and $>19$ is considered to reflect a mild, moderate and severe depression, respectively.

The study was approved by the Institutional Review Board of the Medical Faculty of the University of Göttingen, and informed consent was obtained from all participants.

Genotyping of the 5-HTT promoter polymorphism (5-HTTLPR)

Genomic DNA was prepared from peripheral blood mononuclear cells according to the published protocols [13].

The 5-HTT linked polymorphic region (5-HTTLPR) of the gene encoding SERT (SCL6A4) located on chromosome 17q11.1-12 was amplified by the flanking oligonucleotide primers 5'-GAG GGA CTG AGC TGG ACA AC-3' and 5'-GCA GCA GAC AAC TGT GTT CAT C-3'. The short ( $\mathrm{s}$ ) allele is $44 \mathrm{bp}$ shorter than the long (1) allele due to a 44 bp deletion [7]. PCR was performed in a final solution of $20 \mu$ containing between 200 and $600 \mathrm{ng}$ genomic DNA, $0.2 \mathrm{mM}$ dNTP, $0.2 \mathrm{mM}$ deaza-GTP, $0.5 \mu \mathrm{M}$ of each primer, 2\% dimethylsulfoxide, $2.5 \mathrm{U}$ Taq polymerase in PCR buffer (Promega).

After an initial denaturation for $3 \mathrm{~min}$ at $95^{\circ} \mathrm{C}, 43$ cycles of denaturing at $95^{\circ} \mathrm{C}$ for $30 \mathrm{~s}$, annealing for $30 \mathrm{~s}$ and extension at $72^{\circ} \mathrm{C}$ for $1 \mathrm{~min}$ were performed, followed by a final extension at $72^{\circ} \mathrm{C}$ for $10 \mathrm{~min}$. Annealing was performed at $65^{\circ} \mathrm{C}$ for the first four cycles, $64^{\circ} \mathrm{C}$ for the subsequent four cycles and $63^{\circ} \mathrm{C}$ during the final 35 cycles.

PCR products were visualized on an agarose gel containing ethidium bromide. The variants were detected according to their size relative to a 100 bp DNA ladder (Fig. 1).

\section{Statistical analysis}

To determine whether the genotype frequencies confirmed with Hardy-Weinberg equilibrium, the equivalence test proposed by Wellek was used ( $5 \%$ test level) with $\varepsilon=0.1$ [24]. Odds ratios (ORs) and exact $95 \%$ confidence intervals (CIs) were calculated to compare the genotype frequencies. Differences in genotype frequencies were investigated using an exact Cochrane-Armitage trend test. Differences 
Fig. 1 Example for genotyping of 5-HTTLPR in 18 probands. + Positive control (genotype $l s$ ), - negative control, lanes $\mathrm{P} 1, \mathrm{P} 2$, P6, P8, P13, P17 genotype $l s$, lane $\mathrm{P} 9$ genotype $s$, remaining probands genotype $l l$

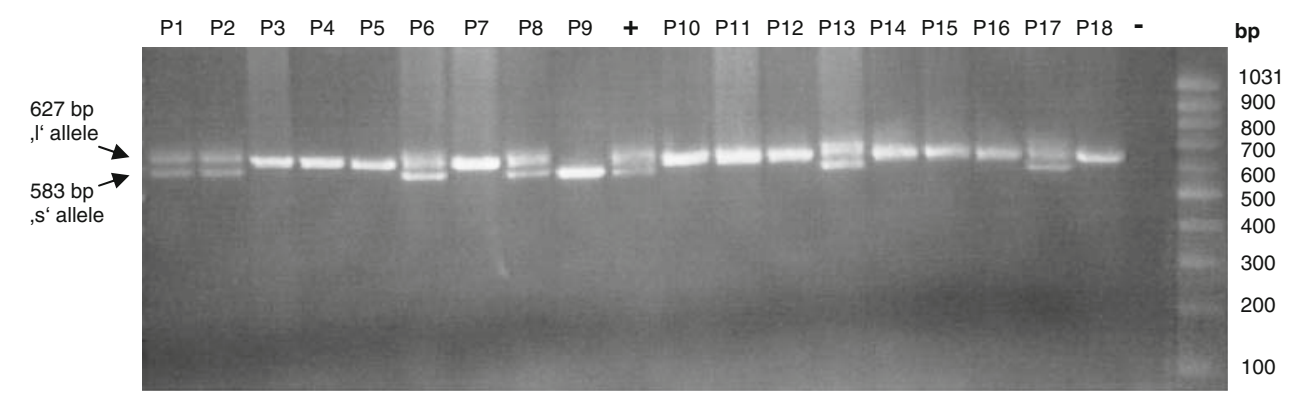

\begin{tabular}{lllll}
\hline & Psoriasis patients & Control group & & \\
& $n=309$ & $n=315$ & & \\
\hline Genotype & $n(\%)$ & $n(\%)$ & OR & \\
ll & $104(33.7)$ & $108(34.3)$ & $1.08(0.86-1.36)$ & \\
ls & $144(46.6)$ & $155(49.2)$ & $1.17(0.74-1.85)$ & 0.496 \\
ss & $61(19.7)$ & $52(16.5)$ & & \\
& Type 1 psoriasis ${ }^{\mathrm{b}}$ & Type 2 psoriasis & \\
& $n=224$ & $n=85$ & & \\
Genotype & $n(\%)$ & $n(\%)$ & & \\
ll & $78(34.8)$ & $26(30.6)$ & $1.28(0.89-1.84)$ & \\
1s & $107(47.8)$ & $37(43.5)$ & $1.63(0.79-3.39)$ & 0.184 \\
ss & $39(17.4)$ & $22(25.9)$ & & \\
\hline
\end{tabular}

Table 1 5-HTTLPR genotype distribution a Two-sided exact $p$ from Cochrane-Armitage trend-test

b Type 1 psoriasis: age at onset $<40$ years

c Type 2 psoriasis: age at onset $\geq 40$ years and $75 \%$ percentiles of the HAM-D were similar in these subgroups (Table 2). As there was a significant difference in the HAM-D between male and female patients, HAM-D values were also compared separately in male and female carriers of 5-HTTLPR genotypes. No significant differences were observed in these subgroups (data not shown).

\section{Discussion}

To the best of our knowledge, this is the first study to investigate a possible relationship between a functionally relevant polymorphism in the promoter of the gene encoding the serotonin transporter and an inflammatory skin disorder. The control group showed genotype frequencies of the 5-HTTLPR polymorphism similar to those reported in an

Table 2 HAM-D in psoriasis patients according to 5-HTTLPR genotype

\begin{tabular}{llll}
\hline HAM-D & \multicolumn{3}{l}{ 5-HTTLPR genotype } \\
\cline { 2 - 4 } & 1l $(n=48)$ & 1s $(n=67)$ & ss $(n=22)$ \\
\hline Mean (SD) & $5.4(5.7)$ & $5.3(5.3)$ & $4.7(5.4)$ \\
Median (range) & $4(0 ; 25)$ & $4(0 ; 21)$ & $4(0 ; 26)$ \\
25. percentile & 1 & 1 & 2 \\
75. percentile & 8 & 7.5 & 7 \\
\hline
\end{tabular}


earlier study with healthy German individuals [12]. We found no association of the 5-HTTLPR polymorphism with psoriasis vulgaris, and the obtained 95\% CIs indicate that major effects are unlikely.

Depressive symptoms have been reported to be more prevalent among psoriatic patients than among healthy individuals [1]. However, it has not been established whether depression is exclusively a consequence of the impaired quality of life and stigmatization of the disease or whether neuroimmunological mechanisms may also contribute to depressive symptoms. The observation of elevated levels of proinflammatory cytokines in depressive patients and the relatively frequent induction of depressive symptoms during the therapeutic application of interferon- $\alpha$ point to a possible role of proinflammatory cytokines in the development of depressive disorders [19]. The reduction of depressive symptoms in patients with psoriasis treated with the TNF-antagonist etanercept parallel to the improvement of skin symptoms [23] could, therefore, be interpreted not only as an indirect effect, but also as a direct effect related to the modulation of peripheral or central neurological functions.

Both depression and psoriasis are complex diseases. Carriage of the 's' allele of the 5-HTTLPR polymorphism has been shown to influence susceptibility to develop depressive symptoms after stressful life events but also in association with other diseases such as Parkinson's disease $[4,14,25]$. In our study, we could not find a significant difference in the HAM-D among carriers of different 5HTTLPR genotypes. However, there are significant limitations to this finding. Low overall HAM-D values among patients with psoriasis in our patient sample may indicate an under-representation of patients with more pronounced depressive symptoms. This is possibly related to the fact that the majority of patients was recruited from a specialized outpatient clinic with optimized patient care. From previous studies, it is evident that different factors are likely to confound the presence and severity of depressive symptoms in psoriasis including gender, severity of skin symptoms and impairment of quality of life [21]. In accordance with the earlier results [18], more pronounced depressive symptoms were observed among female compared with male patients in this study, possibly as a result of genderspecific differences in the prevalence of depression and in the impact of skin diseases on overall well being and selfperception. In light of these findings, it is likely that much larger studies are necessary to establish a relationship between depressive symptoms and genetic variations such as the 5-HTTLPR polymorphism in psoriasis, and that the results obtained with a subgroup of psoriatic patients in this study can only be regarded as preliminary.

The serotonin/serotonin transporter system is a possible link between neuropsychological and immunological func- tions that may particularly be relevant in diseases such as psoriasis that are characterized by stress-induced chronic inflammation and an increased prevalence of depression. In this pilot study, we failed to demonstrate an association between psoriasis and the functionally relevant 5-HTTLPR polymorphisms of the serotonin transporter. There was also no association between depressive symptoms as measured by the HAM-D and carriage of different 5-HTTLRP genotypes in a subgroup of patients with psoriasis. This does not exclude a small contribution of the 5-HTTLPR polymorphism to psoriasis susceptibility or a modulatory effect on the development of depressive symptoms in patients affected by the disease. The specific limitation of the study related to the small number of individuals enrolled is underlined by recent studies indicating that analysis of several thousand individuals may be necessary to detect associations between SNPs of genes involved in psoriasis pathophysiology and the disease [16]. However, smaller studies with hundreds of patients have, for example, been able to identify association between the 5-HTTLPR polymorphism and anxiety-related personality traits in line with the conclusion that the findings from the present investigation at least argue against a major role of the 5-HTTLPR polymorphism in psoriasis [22]. In addition, it may be necessary to analyse genetic influences on depression separately in male and female patients with psoriasis, as depressive symptoms tend to be more severe in woman - as in our study - and genetic effects of the 5-HTTLPR may be superimposed by gender effects. Finally, other functionally relevant genetic variations of the serotonergic system have been identified including a variable number of tandem repeat polymorphism in intron 2 of the 5-HTT gene and polymorphism of serotonin receptors that could play a role in the pathogenesis of psoriasis and depressive symptoms in psoriasis patients [2]. Larger prospective trials are needed to evaluate the genetic basis of the complex interaction of psoriasis, environmental stressors, gender and development of depressive symptoms.

Acknowledgments We thank Melanie Walter and Dajana Meinhardt for excellent technical assistance. This work was supported by a scholarship from the Deutscher Psoriasis Bund to GS and RM.

Open Access This article is distributed under the terms of the Creative Commons Attribution Noncommercial License which permits any noncommercial use, distribution, and reproduction in any medium, provided the original author(s) and source are credited.

\section{References}

1. Akay A, Pekcanlar A, Bozdag KE, Altintas L, Karaman A (2002) Assessment of depression in subjects with psoriasis vulgaris and lichen planus. J Eur Acad Dermatol Venereol 16:347-352. doi:10.1046/j.1468-3083.2002.00467.x 
2. Beretta L, Cossu M, Marchini M, Cappiello F, Artoni A, Motta G, Scorza R (2008) A polymorphism in the human serotonin 5-HT2A receptor gene may protect against systemic sclerosis by reducing platelet aggregation. Arthritis Res Ther 10:R103. doi:10.1186/ ar2495

3. Bowcock AM, Krueger JG (2005) Getting under the skin: the immunogenetics of psoriasis. Nat Rev Immunol 5:699-711. doi:10.1038/nri1689

4. Caspi A, Sugden K, Moffitt TE, Taylor A, Craig IW, Harrington H, McClay J, Mill J, Martin J, Braithwaite A, Poulton R (2003) Influence of life stress on depression: moderation by a polymorphism in the 5-HTT gene. Science 301:386-389. doi:10.1126/science. 1083968

5. Eddahibi S, Humbert M, Fadel E, Raffestin B, Darmon M, Capron F, Simonneau G, Dartevelle P, Hamon M, Adnot S (2001) Serotonin transporter overexpression is responsible for pulmonary artery smooth muscle hyperplasia in primary pulmonary hypertension. $\mathbf{J}$ Clin Invest 108:1141-1150

6. Essmann W (1978) Serotonin distribution in tissue and fluids. In: WB Essmann (ed) Serotonin in health and disease, vol 1. Spectrum, New York

7. Heils A, Teufel A, Petri S, Stober G, Riederer P, Bengel D, Lesch KP (1996) Allelic variation of human serotonin transporter gene expression. J Neurochem 66:2621-2624

8. Idzko M, Panther E, Stratz C, Muller T, Bayer H, Zissel G, Durk T, Sorichter S, Di Virgilio F, Geissler M, Fiebich B, Herouy Y, Elsner P, Norgauer J, Ferrari D (2004) The serotoninergic receptors of human dendritic cells: identification and coupling to cytokine release. J Immunol 172:6011-6019

9. Kushnir-Sukhov NM, Gilfillan AM, Coleman JW, Brown JM, Bruening S, Toth M, Metcalfe DD (2006) 5-hydroxytryptamine induces mast cell adhesion and migration. J Immunol 177:6422-6432

10. Lesch KP, Mössner R (1998) Genetically driven variation in serotonin uptake: is there a link to affective spectrum, neurodevelopmental, and neurodegenerative disorders? Biol Psychiatry 44:179-192. doi:10.1016/S0006-3223(98)00121-8

11. Li D, He L (2007) Meta-analysis supports association between serotonin transporter (5-HTT) and suicidal behavior. Mol Psychiatry 12:47-54. doi:10.1038/sj.mp.4001890

12. Marziniak M, Mossner R, Schmitt A, Lesch KP, Sommer C (2005) A functional serotonin transporter gene polymorphism is associated with migraine with aura. Neurology 64:157-159. doi: $10.1159 / 000088791$

13. Miller SA, Dykes DD, Polesky HF (1988) A simple salting out procedure for extracting DNA from human nucleated cells. Nucleic Acids Res 16:1215. doi:10.1093/nar/16.3.1215

14. Mössner R, Henneberg A, Schmitt A, Syagailo YV, Grassle M, Hennig T, Simantov R, Gerlach M, Riederer P, Lesch KP (2001) Allelic variation of serotonin transporter expression is associated with depression in Parkinson's disease. Mol Psychiatry 6:350 352. doi:10.1038/sj.mp.4000849

15. Mössner R, Lesch KP (1998) Role of serotonin in the immune system and in neuroimmune interactions. Brain Behav Immun 12:249-271. doi:10.1006/brbi.1998.0532

16. Nair RP, Ruether A, Stuart PE, Jenisch S, Tejasvi T, Hiremagalore R, Schreiber S, Kabelitz D, Lim HW, Voorhees JJ, Christophers E, Elder JT, Weichenthal M (2008) Polymorphisms of the IL12B and IL23R genes are associated with psoriasis. J Invest Dermatol 128:1653-1661. doi:10.1038/sj.jid.5701255

17. O'Connell PJ, Wang X, Leon-Ponte M, Griffiths C, Pingle SC, Ahern GP (2006) A novel form of immune signaling revealed by transmission of the inflammatory mediator serotonin between dendritic cells and T-cells. Blood 107:1010-1017. doi:10.1182/blood2005-07-2903

18. Picardi A, Mazzotti E, Pasquini P (2006) Prevalence and correlates of suicidal ideation among patients with skin disease. J Am Acad Dermatol 54:420-426. doi:10.1016/j.jaad.2005.11.1103

19. Raison CL, Capuron L, Miller AH (2006) Cytokines sing the blues: inflammation and the pathogenesis of depression. Trends Immunol 27:24-31. doi:10.1016/j.it.2005.11.006

20. Reich K, Mössner R, König IR, Westphal G, Ziegler A, Neumann C (2002) Promoter polymorphisms of the genes encoding tumor necrosis factor-alpha and interleukin-1 beta are associated with different subtypes of psoriasis characterized by early and late disease onset. J Invest Dermatol 118:155-163. doi:10.1046/j.0022202x.2001.01642.x

21. Schmitt JM, Ford DE (2007) Role of depression in quality of life for patients with psoriasis. Dermatology 215:17-27. doi:10.1159/ 000102029

22. Thierry N, Willeit M, Praschak-Rieder N, Zill P, Hornik K, Neumeister A, Lenzinger E, Stastny J, Hilger E, Konstantinidis A, Aschauer H, Ackenheil M, Bondy B, Kasper S (2004) Serotonin transporter promoter gene polymorphic region (5-HTTLPR) and personality in female patients with seasonal affective disorder and in healthy controls. Eur Neuropsychopharmacol 14:53-58. doi:10.1016/S0924-977X(03)00064-6

23. Tyring S, Gottlieb A, Papp K, Gordon K, Leonardi C, Wang A, Lalla D, Woolley M, Jahreis A, Zitnik R, Cella D, Krishnan R (2006) Etanercept and clinical outcomes, fatigue, and depression in psoriasis: double-blind placebo-controlled randomised phase III trial. Lancet 367:29-35. doi:10.1016/S0140-6736(05)67763-X

24. Wellek S (2004) Tests for establishing compatibility of an observed genotype distribution with Hardy-Weinberg equilibrium in the case of a biallelic locus. Biometrics 60:694-703. doi:10.1111/ j.0006-341X.2004.00219.x

25. Zammit S, Owen MJ (2006) Stressful life events, 5-HTT genotype and risk of depression. Br J Psychiatry 188:199-201. doi:10.1192/ bjp.bp.105.020644 